\title{
A Combined Treatment with Myo-Inositol and Monacolin K Improve the Androgen and Lipid Profiles of Insulin-Resistant PCOS Patients
}

\author{
Vincenzo De Leo*, Maria Concetta Musacchio, Valentina Cappelli, Alessandra Di Sabatino, Claudia Tosti and Paola Piomboni
}

Molecular Medicine and Development Department, Obstetrics and Gynecology Clinic, University of Siena, Italy

\section{Abstract}

Objective: We sought to assess and compare the effects of myo-inositol combined with monacolin k (Group A) versus inositol only (Group B) and metformin (Group C), on the clinical, hormonal, metabolic and lipid profiles of insulin-resistant PCOS patients.

Study design: 60 insulin resistant PCOS patients were randomly assigned into three groups. All groups were treated for 6 months with either myo-inositol and monacolin $\mathrm{k}$, inositol only or metformin. Patients clinical, hormonal and metabolic profiles were compared between all groups, and within each group, prior and following the aforementioned treatment.

Results: All treatment arms improved patients' clinical, hormonal and metabolic profiles, with a tendency toward better results in patients using the combination of myo-inositol and monacolin $\mathrm{k}$.

Conclusion: The combined treatment with the natural products: monacolin $\mathrm{K}$ and myo-inositol represents a valid and well tolerated alternative to the common medical therapy, improving the PCOS related symptoms, with minimal side effects.

Keywords: Cholesterol; Inositol; Insulin resistance; Monacolin k; PCOS

\section{Introduction}

Polycystic Ovary Syndrome (PCOS) is a multifactorial endocrinopathy, affecting $5-10 \%$ of reproductive age women. The clinical presentation varies from eumenorrhea and a sonographic picture of polycystic ovaries but with subtle phenotypic abnormalities or signs of hyperandrogenism, to advanced Stein and Leventhal syndrome [1,2] and its associated long- term sequelae. Moreover, most women with PCOS also exhibit metabolic syndrome features, including insulin resistance, obesity and dyslipidaemia [3-5]. For a long time, treatments for PCOS were focused on androgen suppression and induction of ovulation. More recently it has been clearly demonstrated that the effective reduction of insulin resistance obtained with metformin restores regular menstrual cycles, ovulation and therefore fertility [6,7]. This substance has an insulin-sensitizing activity and it is currently used to reduce blood sugar levels in patients with diabetes mellitus since it improves the peripheral utilization of glucose, acting on the liver by increasing insulin sensitivity and inhibiting glucose production, whereas it improves glucose storage and utilization in skeletal muscle cells $[8,9]$. Interestingly it is been clearly demonstrated that metformin improves insulin action at least in part, by increasing insulin mediated release of D-Chiro-Inositol Phosphoglycan (DCIIPG) in PCOS women [10].

The Inositol Phosphoglycans (IPGs) are putative mediators in nonclassical insulin signaling cascade for glucose uptake and use, they play an important role in cell development and morphogenesis. Insulinresistant PCOS women display decreased insulin-stimulated release of D-Chiro-Inositol (DCI)-Containing IPGs (DCI-IPGs) during an oral glucose tolerance test, as compared to control women [11], which was related to impaired coupling between insulin action and the release of the DCI-IPG $[12,13]$.

Oral nutritional supplementation with inositol, part of the vitamin B complex (B8) and an intracellular second messenger, was demonstrated to enhance insulin sensitivity and improves the clinical and hormonal characteristics of PCOS patients [14-18]. Moreover, inositol supplementation was shown to restore spontaneous ovulation with the consequent increase in conception, either alone [19-21] or when combined with gonadotropins [22].

Systemic inflammation associated with endothelial vascular dysfunction and metabolic dysfunction are commonly present in women with PCOS, with the consequent exaggerated risk for Cardiovascular Disease (CVD), compared with those without PCOS [23-25]. Moreover, Triglyceride (TG), Low-Density Lipoprotein (LDL) and non-high-density lipoprotein (HDL) cholesterol levels are also higher in PCOS as compared with non-PCOS women. Red yeast rice, a Chinese dietary supplement, has gained popularity due to its properties as a natural statin. It contains varying amounts of natural monacolin $\mathrm{K}$ (mevinolin) - a metabolite of Monascus rubber, which specifically inhibit 3-hydroxy-3-methylglutaryl (HMG)-CoA reductase, the ratelimiting enzyme in cholesterol synthetic pathway [18]

Monacolin $\mathrm{K}$ was suggested to have a similar effect on lipid metabolism, as shown for the mechanism of action of pharmacological statins [26], and it was demonstrated to effectively reduce the levels of cholesterol in patients with hypercholesterolemia [27]. Moreover, its ability to inhibit steroid synthesis was claimed to be responsible for the observed decrease in hyperandrogenism, which may further restore ovulation in those PCOS patients, as was already demonstrated following the use of simvastatin alone or in combination with metformin [28]. Furthermore, the antioxidative properties of statins and monacolin $\mathrm{K}$, may further control cellular proliferation and improve ovulatory function [29].

*Corresponding author: Prof. Vincenzo De Leo, Molecular Medicine and Development Department University of Siena, Italy, Tel: +390577233465; Fax +390577233454; E-mail: vincenzo.deleo@unisi.it

Received July 30, 2013; Accepted September 21, 2013; Published Septembe 23, 2013

Citation: Leo VD, Musacchio MC, Cappelli V, Sabatino AD, Tosti C, et al. (2013) A Combined Treatment with Myo-Inositol and Monacolin $\mathrm{K}$ Improve the Androgen and Lipid Profiles of Insulin-Resistant PCOS Patients. J Metabolic Synd 2: 127. doi:10.4172/2167-0943.1000127

Copyright: $\odot 2013$ Leo VD, et al. This is an open-access article distributed under the terms of the Creative Commons Attribution License, which permits unrestricted use, distribution, and reproduction in any medium, provided the original author and source are credited. 
Citation: Leo VD, Musacchio MC, Cappelli V, Sabatino AD, Tosti C, et al. (2013) A Combined Treatment with Myo-Inositol and Monacolin K Improve the Androgen and Lipid Profiles of Insulin-Resistant PCOS Patients. J Metabolic Synd 2: 127. doi:10.4172/2167-0943.1000127

Page 2 of 5

Prompted by these findings, we sought to assess and compare the effects of myo- inositol combined with monacolin $\mathrm{k}$ versus inositol alone and versus metformin treatment, on the clinical, hormonal, metabolic and lipid profiles of insulin-resistant PCOS patients.

\section{Patients and Methods}

The study population consisted of 60 PCOS patients, aged between 24 and 32 years, with insulin resistance (as evaluated by homeostasis model assessment of insulin resistance-HOMA index). Informed consent was obtained from all patients before participation in the study, and the study was approved by the Clinical Research Committee. All patients met the PCOS criterion of the recent ESHRE/ASRM consensus [1], with the exclusion of other endocrinopathies. HOMA index was calculated as the product of fasting plasma insulin $(\mathrm{mU} / \mathrm{L})$ and glucose ( $\mathrm{mmol} / \mathrm{L})$ concentrations divided by $22.5[23,30]$.

Upon enrollment, all patients underwent a basic workup, including the completion of a referral status form that covered demographic

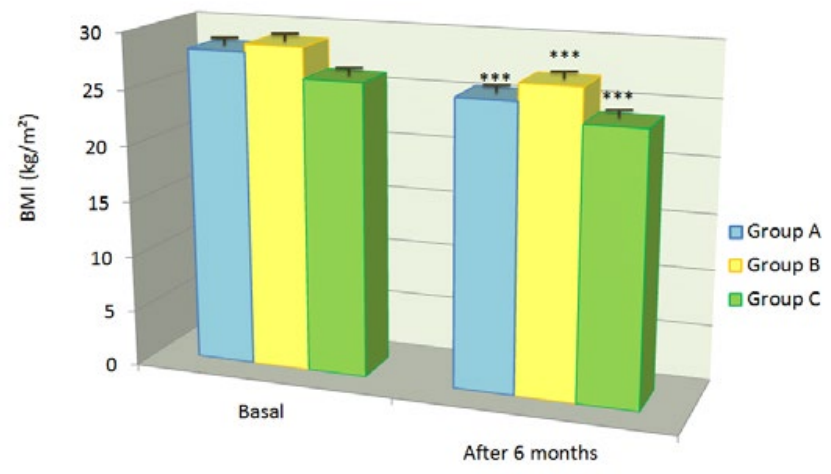

Figure 1: Evaluation of basal BMI and after 6 months of treatment in women treated with monacolin $\mathrm{k}+$ myo-inositol (group A), inositol only (group B), or metformin (Group C). Values are presented as median and IC $95 \%$. ${ }^{*}=p<0.05$, ${ }^{* *}=p<0.005,{ }^{* * *}=p<0.001$. characteristics, basic medical and gynecological history and comprehensive physical examination, including Body Mass Index (BMI) and Ferriman-Gallwey score [28] evaluations. We considered hirsute women with Ferriman-Gallwey score $>8$ [31,32]. Moreover, blood was drawn from all patients for hormonal [FSH, LH, Total Testosterone (TT), free Testosterone (fT), SHBG and Androstenedione (A)], metabolic (glucose, insulin) and lipid (total cholesterol, LDL, HDL, triglycerides) profiles.

Eligible women were randomly assigned into three groups. Group A $(\mathrm{n}=20)$ achieved myo-inositol $1,5 \mathrm{~g}$ and monacolin $\mathrm{k} 3 \mathrm{~g}$ (AZELIPProgineFarmaceutici), twice a day, for 6 months; and Group B $(n=20)$ was treated with a galenic preparation containing inositol $1,5 \mathrm{~g}$ twice a day for 6 months and Group C $(n=20)$ was treated with metformin 850 $\mathrm{mg}$ twice a day, for 6 months.

After 6 months of therapy, all patients had repeated the aforementioned evaluations.

\section{Statistical analysis}

Statistical analysis was performed by SPSS statistical software version 17 (SPSS I Chicago, IL, USA), with Mann-Whitney test, as appropriate. Results are presented as medians \pm confidence interval (IC) $95 \%$; $<<0.05$ was considered significant.

\section{Results}

The baseline clinical, hormonal, metabolic and lipid profiles were comparable between the three study groups (Table 1). Following 6 months of treatment, the duration of the menstrual cycles was significantly shortened in all study groups (Table 1). Moreover, while all the BMI (Table 1 and Figure 1) and the Ferriman-Gallwey (Table 1) were significantly improved after 6 months of treatments in the three study groups, the reductions were pronounced in group A (myoinositol+monacolin k) compare to group B (inositol only).

While, we observed no differences in FSH levels following the 6-months, LH levels were significantly reduced in all three patient

\begin{tabular}{|c|c|c|c|c|c|c|c|c|c|}
\hline & \multicolumn{3}{|c|}{ GROUP A } & \multicolumn{3}{|c|}{ GROUP B } & \multicolumn{3}{|c|}{ GROUP C } \\
\hline & BASAL & $\begin{array}{c}\text { AFTER } \\
6 \text { MONTHS }\end{array}$ & $\mathbf{P}$ & BASAL & $\begin{array}{c}\text { AFTER } \\
6 \text { MONTHS }\end{array}$ & $\mathbf{P}$ & BASAL & $\begin{array}{c}\text { AFTER } \\
6 \text { MONTHS }\end{array}$ & $\mathbf{P}$ \\
\hline BMI $\left(\mathrm{kg} / \mathrm{m}^{2}\right)$ & $28.2 \pm 1.3$ & $25.7 \pm 1.1$ & 0.001 & $28.8 \pm 0.7$ & $27.1 \pm 1$ & 0.001 & $26.2 \pm 0.5$ & $24 \pm 0.6$ & 0.001 \\
\hline Menstrual cycles(days) & $45-60$ & $30-35$ & 0.001 & $45-60$ & $33-38$ & 0.001 & $45-60$ & $30-38$ & 0.001 \\
\hline $\begin{array}{l}\text { F.Gallwey } \\
\text { (score) }\end{array}$ & $11.7 \pm 2.7$ & $7 \pm 3.9$ & 0.001 & $11 \pm 1$ & $9 \pm 4$ & 0.035 & $11 \pm 2$ & $9 \pm 1$ & 0.035 \\
\hline LH $(\mathrm{mU} / \mathrm{ml})$ & $10.3 \pm 1.3$ & $7.3 \pm 0.4$ & 0.001 & $11.1 \pm 0.7$ & $8.6 \pm 0.4$ & 0.001 & $11.5 \pm 1.1$ & $7.9 \pm 0.7$ & 0.001 \\
\hline FSH (mU/ml) & $4.5 \pm 0.3$ & $5.8 \pm 0.6$ & 0.040 & $5.5 \pm 0.2$ & $6.1 \pm 0.3$ & 0.040 & $4.9 \pm 052$ & $5.8 \pm 0.3$ & 0.040 \\
\hline $\mathbf{T}(\mathrm{pg} / \mathrm{ml})$ & $0.8 \pm 0.1$ & $0.5 \pm 0.1$ & 0.040 & $1 \pm 0.1$ & $0.8 \pm 0.1$ & 0.040 & $0.8 \pm 0.1$ & $0.6 \pm 0.1$ & 0.040 \\
\hline $\mathrm{fT}(\mathrm{pg} / \mathrm{ml})$ & $1.2 \pm 0.2$ & $0.6 \pm 0.1$ & 0.001 & $1.3 \pm 0.4$ & $1.1 \pm 0.3$ & 0.032 & $1.3 \pm 0.2$ & $0.8 \pm 0.1$ & 0.040 \\
\hline $\mathbf{A}(\mathrm{ng} / \mathrm{ml})$ & $2.0 \pm 0.1$ & $0.9 \pm 0.1$ & 0.001 & $2 \pm 0.2$ & $1.7 \pm 0.1$ & 0.048 & $2.6 \pm 0.2$ & $1.8 \pm 0.2$ & 0.001 \\
\hline SHBG (nMol/L) & $42.5 \pm 3.2$ & $96 \pm 10.8$ & 0.001 & $38 \pm 3.2$ & $50 \pm 2.7$ & 0.367 & $39 \pm 3.7$ & $85 \pm 5.6$ & 0.001 \\
\hline Glucose(mg/dl) & $99.5 \pm 2.1$ & $91 \pm 1.7$ & 0.001 & $100 \pm 1.4$ & $95 \pm 2.1$ & 0.001 & $100.5 \pm 3.1$ & $92.5 \pm 4.2$ & 0.001 \\
\hline Insulin (mU/ml) & $14.1 \pm 2.8$ & $10.2 \pm 1.1$ & 0.001 & $14.5 \pm 0.8$ & $11 \pm 0.6$ & 0.001 & $15 \pm 0.7$ & $10.9 \pm 0.6$ & 0.001 \\
\hline HOMA & $3.8 \pm 0.42$ & $2.5 \pm 0.4$ & 0.001 & $3.8 \pm 0.3$ & $2.7 \pm 0.3$ & 0.001 & $3.2 \pm 0.4$ & $2.4 \pm 0.3$ & 0.001 \\
\hline $\begin{array}{l}\text { Total Cholesterol } \\
\text { (mg/dl) }\end{array}$ & $220 \pm 12.4$ & $194 \pm 8.15$ & 0.001 & $220.7 \pm 5.7$ & $211.2 \pm 5.3$ & 0.040 & $236 \pm 5.2$ & $206 \pm 3.8$ & 0.040 \\
\hline HDL (mg/dl) & $59.5 \pm 3.4$ & $68.5 \pm 3.2$ & 0.001 & $62.1 \pm 4.3$ & $63.1 \pm 4.1$ & 0.359 & $58 \pm 4.2$ & $70 \pm 6.4$ & 0.040 \\
\hline TG (mg/dl) & $164 \pm 9.4$ & $134.2 \pm 9.4$ & 0.001 & $155.5 \pm 9.1$ & $137.4 \pm 15.1$ & 0.008 & $165.5 \pm 4.1$ & $144.5 \pm 12$ & 0.036 \\
\hline LDL (mg/dl) & $127.5 \pm 13.1$ & $96.5 \pm 7.3$ & 0.001 & $198.8 \pm 7.9$ & $174.4 \pm 7.1$ & 0.036 & $198.5 \pm 4.7$ & $167.5 \pm 5.8$ & 0.036 \\
\hline
\end{tabular}

Clinical, hormonal, metabolic and lipidic profiles of the two study group, before and following 6 months of treatment. (Group A: inositol plus monacolin; Group B: inositol only; Group C metformin). Data are presented as median \pm confidence interval (IC) $95 \%$. $P$ values are significative if $p<0.05$

Table 1: Clinical, hormonal, metabolic and lipidic profiles of the three study groups. 
Citation: Leo VD, Musacchio MC, Cappelli V, Sabatino AD, Tosti C, et al. (2013) A Combined Treatment with Myo-Inositol and Monacolin K Improve the Androgen and Lipid Profiles of Insulin-Resistant PCOS Patients. J Metabolic Synd 2: 127. doi:10.4172/2167-0943.1000127

Page 3 of 5

groups with a consequent improvement and normalization of the LH/ FSH ratio to a level below 2 (Table 1).

Androgens levels (TT, fT and A) were significantly reduced in all three groups following treatment (Table 1), but to a lesser degree in group $\mathrm{B}$ and $\mathrm{C}$, as compared to $\mathrm{A}$. This probably results from the significant increase in SHBG levels observed following treatment with myo-inositol + monacolin $\mathrm{k}$ (group $\mathrm{A}, \mathrm{p}<0.001$ ), but not with inositol only (group B, p=0.367).
Considering the glycemic profile, glucose and insulin levels, as well as the HOMA-index were significantly reduced following treatment in both study groups (Table 1). These reductions were more pronounced following treatment in group A, compared to B (Figure 2).

Regarding the lipid profile (Table 1 and Figure 3), total cholesterol level was reduced in all three group but significantly only in group A treated with myo-inositol monacolin $\mathrm{k}$. The same pattern was observed
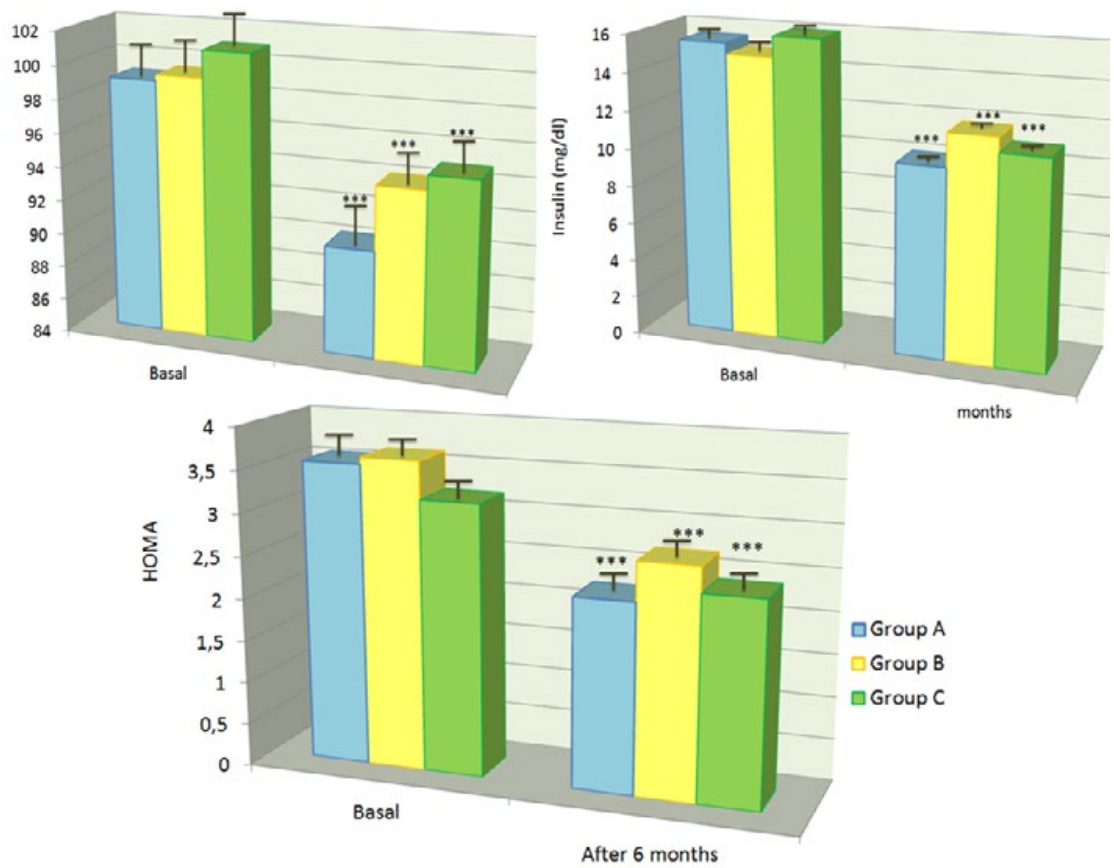

Figure 2: Representation of HOMA, insulin and glucose at basal time and after 6 months of treatment with monacolin $\mathrm{k}+$ myo-inositol (group A), only inositol (group B) or metformin (Group C). Values are presented median and IC $95 \% .{ }^{*}=p<0.05,{ }^{* *}=p<0.005,{ }^{* * *}=p<0.001$.
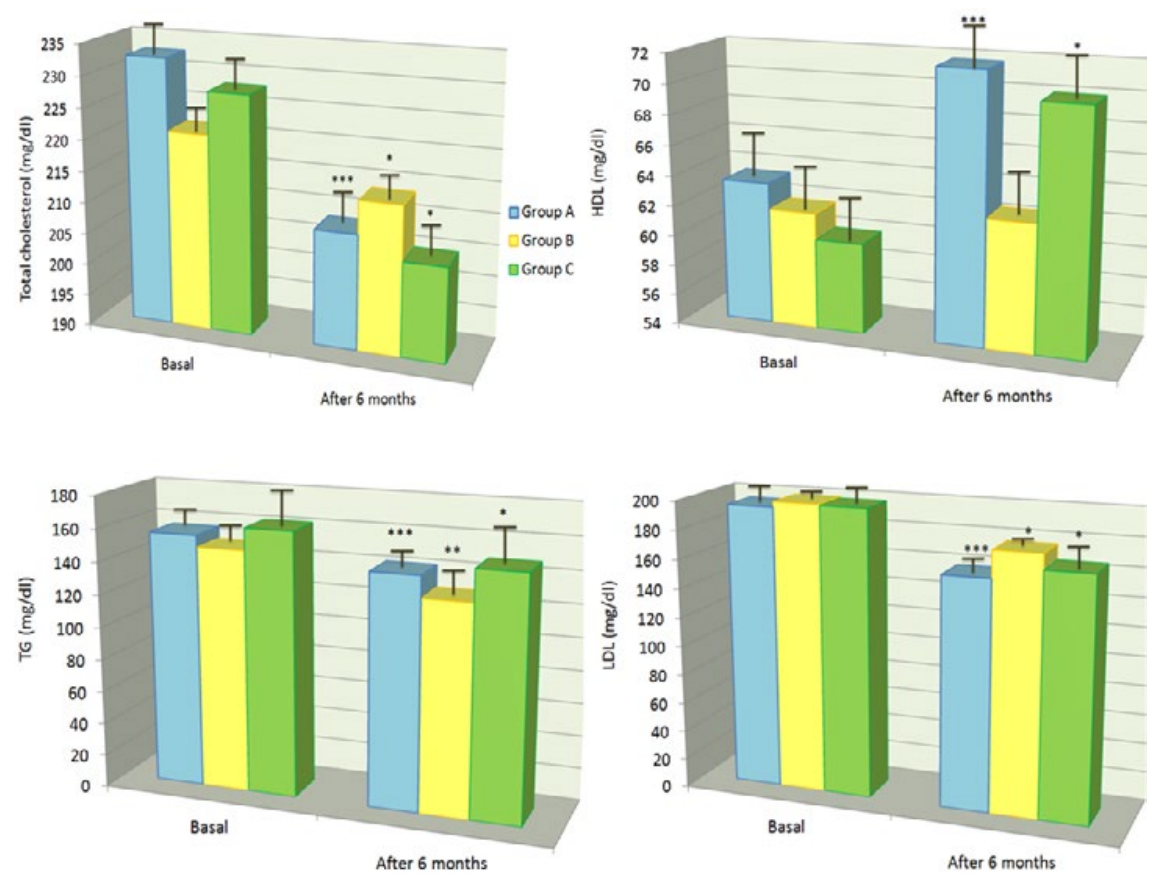

Figure 3: Cholesterol (Chol.), triglicerides (TG), HDL and LDL values at basal time and after 6 months treatment with monacolin $\mathrm{k}+$ myo-inositol (group A), inositol only (group B), or metformin (Group C). Values are presented as median and IC $95 \% .{ }^{*}=p<0.05,{ }^{* *}=p<0.005,{ }^{* * *}=p<0.001$. 
Citation: Leo VD, Musacchio MC, Cappelli V, Sabatino AD, Tosti C, et al. (2013) A Combined Treatment with Myo-Inositol and Monacolin K Improve the Androgen and Lipid Profiles of Insulin-Resistant PCOS Patients. J Metabolic Synd 2: 127. doi:10.4172/2167-0943.1000127

for TG and LDL-cholesterol with significantly reduction in group A, (Figure 3). Furthermore treatment with myo-inositol and monacolin $\mathrm{K}$ (group A) resulted in a significant increase in HDL cholesterol level, no change in inositol only instead (Group B) and metformin treatment (Group C) (Table 1 and Figure 3).

Almost all women in each group have endured well the two treatments: only two women in group A and one in group B reported moderate diarrhea carefully controlled with lactic ferments intake, while the women treated with metformin (Group C) reported severe side effects like nausea and diarrhea and two women interrupted the treatment.

\section{Discussion}

In the present study, we demonstrated that all treatments improved patients' clinical, hormonal and metabolic profiles, with a tendency toward better results using the combination of myo-inositol and monacolin $\mathrm{k}$.

Our data confirm previous observations demonstrating the beneficial effect of inositol on overweight, hyperinsulinemic and hirsute PCOS patients with menstrual irregularities $[17,20]$. Moreover our study confirms that metformin can improve metabolic aspects in PCOS patient, even if the literature is discrepant about metformin effects on lipid, menstrual and ovulation characteristics $[8,9,33,34]$.

Actually, after 6 months of therapy all study groups have demonstrated shorter menstrual cycles, lower Ferriman-Gallwey scores and decreased BMI and LH/FSH ratio. Observations, which are probably the consequence of weight loss and improvement in insulinresistance, associated with inositol intake. In fact, the reduction in BMI was more pronounced in group A (myo-inositol + monacolin k), compare to group B (inositol only).

Ferriman-Gallwey score, as well as androgen levels were significantly reduced in all study groups, with a tendency toward a better improvement following the combined treatment with myoinositol and monacolin $\mathrm{k}$. This probably results from the significant increase in SHBG levels observed following treatment with myoinositol+monacolin $\mathrm{k}[34,35]$.

While glucose, insulin and HOMA index were significantly decreased in all groups, the HOMA index in patients treated with myoinositol and monacolin $\mathrm{k}$ were within the normal range.

Regarding the lipid profile, total cholesterol, triglycerides and LDL levels were significantly reduced in all groups, with a more pronounced reduction in LDL following the combined treatment with myoinositol and monacolin k. Moreover, while HDL cholesterol was not significantly modified in inositol therapy, the combined treatment with myo-inositol and monacolin $\mathrm{k}$ significantly rised in HDL levels. The reduction of plasma lipids has a significative role, since PCOS patients show an increased risk of cardiovascular disease [9], the aforementioned observations emphasize the important role of myo-inositol and monacolin $\mathrm{k}$ intake on lipid metabolism, and more specifically in improving lipid profile and reducing patients' cardiovascular risk.

Since metformin and statins administrations are associated with several side effects such as nausea, vomiting, gastric pain causing the end of therapy [36], the combined treatment with the natural products: monacolin $\mathrm{k}$ and myo-inositol represents a valid alternative, well tolerated and with a similar mode of action. This new combination of myo-inositol and monacolin $\mathrm{k}$ may oppose the etiopathologies responsible for the onset and deterioration of PCOS related symptoms, and may represents a reasonable alternative to other treatments modalities, such as combined oral contraceptive or antiandrogenic drugs, which are associated with a variety of side effects, especially in adolescents. Moreover this natural choice is much more accepted by patients and clinicians who consider metformin only an antidiabetic drug and then other uses are "off label" [37].

\section{References}

1. Rotterdam ESHRE/ASRM- Sponsored PCOS Consensus Workshop Group (2004) Revised 2003 consensus on diagnostic criteria and long-term health risks related to polycystic ovary syndrome. Fertil Steril 81: 19-25.

2. Stein IF, Leventhal ML (1935) Amenorrhea associated with bilateral polycystic ovaries. Am J Obstet Gynecol 29: 181-191.

3. Dunaif A, Graf M, Mandeli J, Laumas V, Dobrjansky A (1987) Characterization of groups of hyperandrogenic women with acanthosis nigricans, impaired glucose tolerance, and/or hyperinsulinemia. J Clin Endocrinol Metab 65: 499-507.

4. Robinson S, Kiddy D, Gelding SV, Willis D, Niththyananthan R, et al. (1993) The relationship of insulin insensitivity to menstrual pattern in women with hyperandrogenism and polycystic ovaries. Clin Endocrinol (Oxf) 39: 351-355.

5. Franks S (2006) Genetic and environmental origins of obesity relevant to reproduction. Reprod Biomed Online 12: 526-531.

6. Glueck CJ, Streicher P, Wang P (2002) Treatment of polycystic ovary syndrome with insulin-lowering agents. Expert Opin Pharmacother 3: 1177-1189.

7. De Leo V, la Marca A, Ditto A, Morgante G, Cianci A (1999) Effects of metformin on gonadotropin-induced ovulation in women with polycystic ovary syndrome. Fertil Steril 72: 282-285.

8. De Leo V, La Marca A (2002) Metformin and FSH for induction of ovulation in women with polycystic ovarian syndrome. Hum Reprod 17: 2481-2482.

9. De Leo V, la Marca A, Petraglia F (2003) Insulin-lowering agents in the management of polycystic ovary syndrome. Endocr Rev 24: 633-667.

10. Baillargeon JP, luorno MJ, Jakubowicz DJ, Apridonidze T, He N, et al. (2004 Metformin therapy increases insulin-stimulated release of d-chiro-inositolcontaining inositolphosphoglycan mediator in women with polycystic ovary syndrome. Clin Endocrinol Metab 89: 242-249.

11. Baillargeon JP, Nestler JE, Ostlund RE, Apridonidze T, Diamanti-Kandarakis E (2008) Greek hyperinsulinemic women, with or without polycystic ovary syndrome, display altered inositols metabolism. Hum Reprod 23: 1439-1446.

12. Baillargeon JP, Iuorno MJ, Apridonidze T, Nestler JE (2010) Uncoupling Between Insulin and Release of a D-Chiro-Inositol-Containing Inositolphosphoglycan Mediator of Insulin Action in Obese Women With Polycystic Ovary Syndrome. Metab Syndr Relat Disord 8: 127-136.

13. Cheang KJ, Baillargeon JP, Essah PA, Ostlund RE Jr, Apridonize T, et al. (2008) Insulin-stimulated release of D-chiro-inositol-containing inositolphosphoglycan mediator correlates with insulin sensitivity in women with polycystic ovary syndrome. Metabolism 57: 1390-1397.

14. Nestler JE, Jakubowicz DJ, Reamer P, Gunn RD, Allan G (1999) Ovulatory and metabolic effects of D-chiro-inositol in the polycystic ovary syndrome. $N$ Engl Med 340: 1314-1320.

15. Iuorno MJ, Jakubowicz DJ, Baillargeon JP, Dillon P, Gunn RD, et al. (2002) Effects of d-chiro-inositol in lean women with the polycystic ovary syndrome. Endocr Pract 8: 417-423.

16. Gerli S, Mignosa M, Di Renzo GC (2003) Effects of inositol on ovarian function and metabolic factors in women with PCOS: a randomized double blind placebo-controlled trial. Eur Rev Med Pharmacol Sci 7: 151-159.

17. Genazzani AD, Lanzoni C, Ricchieri F, Jasonni VM (2008) Myo-inosito administration positively affects hyperinsulinemia and hormonal parameters in overweight patients with polycystic ovary syndrome. Gynecol Endocrinol 24 139-144.

18. Zacchè MM, Caputo L, Filippis $S$, Zacchè G, Dindelli M, et al. (2009) Efficacy of myo-inositol in the treatment of cutaneous disorders in young women with polycystic ovary syndrome. Gynecol Endocrinol 25: 508-513.

19. Papaleo E, Unfer V, Baillargeon JP, De Santis L, Fusi F, et al. (2007) Myoinositol in patients with polycystic ovary syndrome: a novel method for ovulation induction. Gynecol Endocrinol 23: 700-703.

20. Papaleo E, Unfer V, Baillargeon JP, Chiu TT (2009) Contribution of myo-inosito to reproduction. Eur J Obstet Gynecol Reprod Biol 147: 120-123. 
Citation: Leo VD, Musacchio MC, Cappelli V, Sabatino AD, Tosti C, et al. (2013) A Combined Treatment with Myo-Inositol and Monacolin K Improve the Androgen and Lipid Profiles of Insulin-Resistant PCOS Patients. J Metabolic Synd 2: 127. doi:10.4172/2167-0943.1000127

21. Gerli S, Papaleo E, Ferrari A, Di Renzo GC (2007) Randomized, double blind placebo-controlled trial: effects of myo-inositol on ovarian function and metabolic factors in women with PCOS. Eur Rev Med Pharmacol Sci 11: 347354

22. Raffone E, Rizzo P, Benedetto V (2010) Insulin sensitiser agents alone and in co-treatment with r-FSH for ovulation induction in PCOS women. Gynecol Endocrinol 26: 275-280.

23. Amsterdam ESHRE/ASRM-Sponsored 3rd PCOS Consensus Workshop Group (2012) Consensus on women's health aspects of polycystic ovary syndrome (PCOS). Hum Reprod 27: 14-24.

24. Legro RS (2003) Polycystic ovary syndrome and cardiovascular disease: a premature association? Endocr Rev 24: 302-312.

25. Diamanti-Kandarakis E, Kandaraki E, Christakou C, Panidis D (2009) The effect of pharmaceutical intervention on lipid profile in polycystic ovary syndrome. Obes Rev 10: 431-441.

26. Sokalska A, Piotrowski PC, Rzepczynska IJ, Cress A, Duleba AJ (2010) Statins inhibit growth of human theca-interstitial cells in PCOS and non-PCOS tissues independently of cholesterol availability. J Clin Endocrinol Metab 95: 53905394.

27. Feuerstein JS, Bjerke WS (2012) Powdered red yeast rice and plant stanols and sterols to lower cholesterol. J Diet Suppl 9: 110-115.

28. Kazerooni T, Shojaei-Baghini A, Dehbashi S, Asadi N, Ghaffarpasand F, et al (2010) Effects of metformin plus simvastatin on polycystic ovary syndrome: a prospective, randomized, double-blind, placebo-controlled study. Fertil Steril 94: 2208-2213.
29. De Leo V, Musacchio MC, Palermo V, Di Sabatino A, Morgante G, et al. (2009) Polycystic ovary syndrome and metabolic comorbidities: therapeutic options. Drugs Today (Barc) 45: 763-775.

30. Hosker JP, Matthews DR, Rudenski AS, Burnett MA, Darling P, et al. (1985) Continuous infusion of glucose with model assessment: measurement of insulin resistance and beta-cell function in man. Diabetologia 28: 401-411.

31. FERRIMAN D, GALLWEY JD (1961) Clinical assessment of body hair growth in women. J Clin Endocrinol Metab 21: 1440-1447.

32. Goodman N, Bledsoe M, Cobin R, Futterweit W, Goldzieher J, et al. (2001) American Association of Clinical Endocrinologists Hyperandrogenism Guidelines. Endocrine Practice 7: 120-134.

33. Tang T, Lord JM, Norman RJ, Yasmin E, Balen AH (2010) Insulin-sensitising drugs (metformin, rosiglitazone, pioglitazone, D-chiro-inositol) for women with polycystic ovary syndrome, oligo amenorrhoea and subfertility. Cochrane Database Syst Rev.

34. De Leo V, Di Sabatino A, Musacchio MC, Morgante G, Scolaro V, et al. (2010) Effect of oral contraceptives on markers of hyperandrogenism and SHBG in women with polycystic ovary syndrome. Contraception 82: 276-280.

35. Lee CL, Pan TM (2012) Development of Monascus fermentation technology for high hypolipidemic effect. Appl Microbiol Biotechnol 94: 1449-1459.

36. Practice Committee of American Society for Reproductive Medicine (2008) Use of insulin-sensitizing agents in the treatment of polycystic ovary syndrome. Fertil Steril 90: S69-73.

37. Hsia Y, Dawoud D, Sutcliffe AG, Viner RM, Kinra S, et al. (2012) Unlicensed use of metformin in children and adolescents in the UK. Br J Clin Pharmacol 73: $135-139$. 